\title{
Age differences in tracking characters during narrative comprehension
}

\author{
Soo Rim Noh and Elizabeth A. L. Stine-Morrow \\ University of Illinois, Urbana-Champaign, Illinois
}

\begin{abstract}
Understanding a narrative situation depends on keeping track of multiple characters that enter and exit dynamically as the plot unfolds. We investigated age differences in this process during narrative comprehension. In Experiment 1, we used a probe recognition paradigm to examine the effect of age on the accessibility of a previous character when another character was subsequently introduced. In Experiment 2, reading time was measured to examine age differences in the encoding of a new character after another had already been introduced. Our findings show that older readers have particular difficulty both in accessing the initial character after a new character is introduced and in thoroughly encoding a new character while other characters inhabit the discourse world. We attribute these differences to age differences in working memory that make it difficult to access a backgrounded character when a new character is in focus and to distinctively encode a new character when maintenance of another character is already consuming attentional resources.
\end{abstract}

To understand narratives, readers create a situation model that simulates experience in the real world (Zwaan, Magliano, \& Graesser, 1995; Zwaan \& Radvansky, 1998; Zwaan \& Rapp, 2006). This situation model is thought to be constructed and updated along multiple dimensions, such as the existence and properties of characters that inhabit the discourse world and their spatial/temporal situation. The specific interest of the present study was how younger and older readers create a mental representation of a narrative when multiple characters enter and exit dynamically as the plot unfolds. Some have argued that situation model processing appears to be largely preserved with aging (Radvansky, Curiel, Zwaan, \& Copeland, 2001; Radvansky \& Dijkstra, 2007; Stine-Morrow, Morrow, \& Leno, 2002), but little research has been focused on the effects of age on the ability to track multiple characters. Given possible resource constraints in tracking multiple characters (Gernsbacher, Robertson, Palladino, \& Werner, 2004), one might expect that this could be an age-sensitive aspect of situation model construction.

\section{Tracking Characters During \\ Narrative Processing}

The process of tracking characters during narrative understanding has been modeled both as a waxing and waning of the activation associated with each character in order to keep current characters in focus (the landscape model; Rapp \& van den Broek, 2005; van den Broek, Rapp, \& Kendeou, 2005) and as structure building of a representation around the individual character (Gernsbacher et al., 2004). Readers require more processing time when a new character is introduced in a text (e.g., Noh et al., 2007;
Radvansky et al., 2001; Rinck \& Weber, 2003). Such increases in reading times are consistent with both of these frameworks. Interestingly, readers tend to actively update characters even when their focus of attention is directed to other situational dimensions (such as space and time) through explicit instruction (Therriault, Rinck, \& Zwaan, 2006), suggesting that tracking characters is fundamental to building a coherent situation model of the narrative.

Some studies examining the tracking of multiple narrative characters have been focused on accessibility (Gernsbacher et al., 2004; Gerrig \& McKoon, 2001; Lea, Mason, Albrecht, Birch, \& Myers, 1998). In Gernsbacher et al.'s (2004) study, young adult participants read narrative texts in which a character (e.g., Patty) is introduced in the first paragraph. Accessibility of the initial character was probed before and after a second paragraph in which the initial character was rementioned (e.g., Patty), a new character was introduced (e.g., Jack), or no character was mentioned (i.e., the baseline). In order to determine the change in the accessibility of the initial character as a function of whether a new character has been introduced, probe response latency and error rates in verifying the name of the initial character (i.e., Patty) were measured. Gernsbacher et al. (2004) found that, relative to the baseline condition, access to the initial character was slower and less accurate when a new character was introduced but was faster and more accurate when the character was rementioned.

The authors explained these findings according to the cognitive mechanisms of enhancement and suppression, suggested by the structure-building framework (e.g., Gernsbacher, 1990, 1997): When a new character is introduced into the narrative, the initial character becomes 
less accessible as the reader suppresses the activation of that character to focus on the new character. In that way, the reader can build a new substructure of text so that the previous character does not interfere with constructing the representation of the new character. Furthermore, the difference in character accessibility between the baseline and the remention condition suggests that activation of a character may fade somewhat in the absence of explicit mention but that the character becomes more accessible when reintroduced. These findings are consistent with the idea that characters compete for activation within a limited-capacity working memory, so that managing multiple characters involves the effective control of resources to keep the most relevant character in working memory (e.g., Rapp \& van den Broek, 2005; van den Broek et al., 2005).

\section{Aging and Narrative Processing}

Much research has demonstrated that, although agerelated declines in language processing are especially common for propositional (textbase) processes, which are resource demanding (Johnson, 2003; Thornton \& Light, 2006), little or no decline is observed in situation model processing (Radvansky \& Dijkstra, 2007). Some have argued, then, that aging brings qualitative differences in reading with the construction of a situation model prioritized over the textbase representation (Radvansky et al., 2001; Radvansky \& Dijkstra, 2007; Stine-Morrow et al., 2002). For example, older adults are typically as good as, or better than, younger adults at updating the spatial situation during narrative comprehension (Morrow, Leirer, Altieri, \& Fitzsimmons, 1994; Stine-Morrow et al., 2002) and at updating a character's emotional and motivational state (Radvansky \& Curiel, 1998; Soederberg \& Stine, 1995). Older adults are more attentive to character shifts during reading. For example, when a new character is introduced, older adults tend to disproportionately increase their reading time allocation relative to younger adults (Radvansky et al., 2001; see Noh et al., 2007, for an example of this effect in expository passages). These findings suggest that older readers are able to control attentional resources to instantiate characters in narrative processing at least as well as young adult readers. However, as far as we know, there has been no systematic investigation of age differences in tracking multiple characters in discourse, which would be expected to be relatively demanding of working memory resources (Gernsbacher et al., 2004).

Some studies in which pronoun reference and aging were examined suggest that older adults' ability to track characters may be compromised by the reduction in working memory resources (Light \& Capps, 1986; Morrow, Altieri, \& Leirer, 1992; Morrow, Leirer, \& Altieri, 1992). For example, Morrow, Leirer, and Altieri (1992) showed that older adults were less accurate in referent choice relative to younger adults, especially when the pronoun in a target sentence referred to a minor character who was distant from the pronoun in the surface form. Importantly, the authors found that working memory span was correlated with faster target sentence reading times and that the positive correlation between age and target sentence reading times became nonsignificant when working memory span was partialled out.

\section{The Present Research}

This study was specifically designed to test whether the ability to track narrative characters changes with age. In Experiment 1, we examined the effect of age on the accessibility of the initial character when another character was introduced using Gernsbacher et al.'s (2004) paradigm described earlier. This paradigm allowed us to test whether age-related declines in working memory make it difficult for older adults to access characters once they have been backgrounded. In Experiment 2, we further examined age differences in tracking multiple characters by measuring reading time when a new character was introduced as a function of whether or not another character was already in the narrative. Thus, whereas in Experiment 1, we examined age differences in the ability to access a previous character when a new character became the focus, in Experiment 2 , we examined the ability to refocus attention on a new character.

\section{EXPERIMENT 1}

\section{Method}

Participants. The participants were 47 younger $(M=24$ years, range $=18-35$ years $)$ and 41 older $(M=70$ years, range $=$ 59-84 years) adults recruited from the community in the UrbanaChampaign area through newspaper advertisements and flyers. The participants received $\$ 15$ for their participation, except for a subset of younger adults who were recruited from the participant pool in the Department of Educational Psychology. An additional 3 young and 10 older adults were tested, but their data were removed for excessive comprehension errors (as is described below; cf. Gernsbacher et al., 2004).

All of the participants were native speakers of English and were screened prior to participation for severe neurological or medical impairment (e.g., stroke, Parkinson's, macular degeneration, any diagnosed neurological or learning ability, inability to use both hands) and acceptable visual acuity (i.e., most had 20/30 or better, but 3 participants whose acuity was less than $20 / 30$ were also included, since the experimental passages were large enough for them to read). The sample of participants was $80.7 \%$ Caucasian, $11.4 \%$ African American, $4.5 \%$ Asian, and $3.4 \%$ multiracial ethnicity. Of the total, $1 \%$ of the participants were Hispanic. All of the participants rated their health as good or excellent.

The older adults had more years of formal education than the younger adults $\left[M_{\mathrm{Y}}=15.48, S E=0.26 ; M_{\mathrm{O}}=17.17, S E=0.47\right.$; $t(86)=3.18, p<.01]$. The older and younger participants' scores $\left(M_{\mathrm{Y}}=49.85, S E=1.20 ; M_{\mathrm{O}}=51.30, S E=1.14\right)$ on the vocabulary subtest of the Wechsler revised adult intelligence scale (WAIS-R; Wechsler, 1981) did not differ significantly $(|t|<1)$ but the older participants scored higher on average on the vocabulary section of the Nelson-Denny reading (NDR) test (Form G; Brown, Fishco, \& Hanna, 1993) $\left[M_{\mathrm{Y}}=69.28, S E=1.77 ; M_{\mathrm{O}}=75.51, S E=1.01\right.$; $t(86)=3.06, p<.01]$. The younger adults tended to perform better on the comprehension section of the NDR test than did the older adults $\left[M_{\mathrm{Y}}=65.00, S E=1.79 ; M_{\mathrm{O}}=60.60, S E=1.81 ; t(84)=\right.$ $1.72, p=.09]$. The participants were also administered reading and listening span tasks to measure working memory (see Daneman \& Carpenter, 1980; Stine \& Hindman, 1994). The younger adults scored higher than older adults, as indicated by the mean of these two measures $\left[M_{\mathrm{Y}}=5.33, S E=0.21 ; M_{\mathrm{O}}=4.43, S E=0.16\right.$; $t(86)=3.33, p<.01]$. 
Table 1

Sample Experimental Narrative From Experiment 1

\section{Paragraph 1: Introduction}

Patty quickly looked over the stage. The props were clearly in the wrong places, extra scripts were randomly scattered around, and the backdrops were still wet with paint, but at least they were finished. Patty, at this point a little skeptical, was still determined to make this production work. It did seem a bit overwhelming now that opening night was only two weeks away.

EXPERIMENTAL TEST PROBE 1:

PATTY (for Before Condition) TERRY (for After Condition)

\section{Paragraph 2: Character Manipulation}

Remention condition. Patty, the stage manager, wanted everything ready for Saturday night's dress rehearsal. The crucial step was going to be getting the actors ready. Patty knew that with some effort, the production would eventually come together, and with any luck at all, might even be a success. There was nothing so heartbreaking as getting bad reviews.

New condition. Jack, the stage manager, wanted everything ready for Saturday night's dress rehearsal. The crucial step was going to be getting the actors ready. Jack knew that with some effort, the production would eventually come together, and with any luck at all, might even be a success. There was nothing so heartbreaking as getting bad reviews.

Neither condition (baseline). Everything was supposed to be ready for Saturday night's dress rehearsal. The crucial step was going to be getting the actors ready. With some effort, the production would eventually come together, and with any luck at all, might even be a success. There was nothing so heartbreaking as getting bad reviews.

EXPERIMENTAL TEST PROBE 2:

JACK (for Before Condition) PATTY (for After Condition)

\section{Paragraph 3: Conclusion}

It was what made the first night so important. Everyone knew it, and as opening night approached the tension got higher. It was only a high school performance, but for many of these kids it was the biggest thing they had ever done.

\section{Foil Test Probe: TERRY (for Before Condition) JACK (for After Condition)}

Stimulus materials. The 32 experimental narratives were adapted from Gernsbacher et al. (2004, Experiment 1) and consisted of three paragraphs (see Table 1 for an example). In the first paragraph, a target character (e.g., Patty) was introduced with an event. The second paragraph contained the character manipulation, which had three versions: (1) the remention version, in which the same character (e.g., Patty) was reintroduced; (2) the new version, in which a new character (e.g., Jack) was introduced; and (3) the neither version, in which no character was explicitly mentioned (i.e., the baseline condition). The third paragraph was a conclusion. The names of the characters were typical American first names that are normally assigned to only one gender. In each narrative, the initial character's and the new character's names were matched for length and were opposite in gender.

As was described earlier, a probe recognition task was used to measure the accessibility of the target character, which was always introduced first in the story (e.g., Patty in the example story). The target character's name probe was presented either before or after the second paragraph, creating four probe conditions: a before condition and three after conditions (remention, new, and neither). For the before condition, the remention-version stories were used, but the position of the target character's name probe was placed before the second paragraph, and the foil name probe was presented after the second paragraph. For the after conditions, the participants were presented with the foil name probe before the second paragraph, followed by the target character's name probe after the second paragraph. The participants responded either "yes" or "no" to indicate whether they had seen the target character's name in the story that they were currently reading. In addition, to increase the number of no responses, a filler test point was included after the third paragraph of each story.

Four material sets were created to counterbalance the experimental stories across conditions, so that each story appeared an equal number of times in the four probe conditions (before, remention, new, neither). An additional 16 filler narratives were included to balance the number of yes and no responses. The filler stories had the same three-paragraph structure as the experimental narratives. All of the filler stories were included in each set, and the experimental and filler stories were presented in a fixed randomized order for all of the participants.

Procedure. Each session lasted approximately $2 \mathrm{~h}$. First, the participants were interviewed for background demographics (e.g., age, education, health) and were checked for visual acuity. The participants then completed the WAIS-R vocabulary task, followed by the reading task. At the end of the session, the loaded listening/reading span tasks and the NDR test (the vocabulary and comprehension sections) were administered.

For the reading task, each participant was randomly assigned to one of the four material sets. Each narrative was presented one paragraph at a time on a Macintosh G3 computer using Power Laboratory software (Chute \& Westall, 1996) in 34-point Courier New font. The participants were asked to read at their own pace for comprehension. They began with two practice stories similar in form to the experimental narratives. The participants were told to begin each story by pressing the ADVANCE key on the computer keyboard, which was followed by a ready signal that appeared in the center of the screen. The participants then read each story one paragraph at a time by pressing the ADVANCE key. Immediately after each paragraph, the participants saw a probe name in the center of the screen and were asked to press the YES or No key on the keyboard (on the correct side according to their handedness) in order to indicate whether they recognize this character as having been in the story that they were currently reading (and not just in the last paragraph). The participants were instructed to respond to the test names as quickly and as accurately as possible and were told to keep their index and middle fingers on the keyboard to respond to the probe recognition task. Finally, in order to encourage the participants' comprehension, they were periodically asked to write continuations for some stories, but only when they saw the sentence "Please continue the story" on the screen.

\section{Results and Discussion}

The accessibility of the target character was examined by measuring recognition latency (in milliseconds) and recognition error rates in responding to the name probe. 
Table 2

Means and Standard Errors of Recognition Errors (\%) As a Function of Age and Probe Condition for Experiment 1

\begin{tabular}{|c|c|c|c|c|c|c|}
\hline \multirow[b]{2}{*}{ Probe Condition } & \multicolumn{2}{|c|}{ Young } & \multicolumn{2}{|c|}{ Old } & \multicolumn{2}{|c|}{$\begin{array}{c}\text { All } \\
\text { Participants } \\
\end{array}$} \\
\hline & $M$ & $S E$ & $M$ & $S E$ & $M$ & $S E$ \\
\hline Before second paragraph & 2.17 & 0.82 & 1.52 & 0.87 & 1.85 & 0.60 \\
\hline \multicolumn{7}{|l|}{ After second paragraph } \\
\hline Remention & 0.54 & 0.43 & 0.92 & 0.46 & 0.73 & 0.32 \\
\hline New & 11.69 & 1.71 & 8.89 & 1.81 & 10.29 & 1.25 \\
\hline Neither (baseline) & 5.86 & 1.43 & 7.08 & 1.51 & 6.47 & 1.04 \\
\hline Overall & 5.07 & 0.76 & 4.60 & 0.80 & 4.83 & 0.55 \\
\hline
\end{tabular}

The data from participants who failed to meet the preestablished criterion of better-than-chance recognition performance (i.e., at least five correct out of eight total trials) for each type of probe condition (before, remention, new, and neither [baseline]) were excluded from the experiment. The data for 3 young and 10 older adults were removed because of excessive comprehension errors. We also screened recognition times for outliers greater than 2.5 standard deviations $(S D \mathrm{~s})$ above the mean for each participant within each probe condition, but none of the responses were actually removed by this criterion.

A 2 (age: young, old) $\times 4$ (probe condition: before, remention, new, baseline) repeated measures ANOVA was separately conducted on the recognition latency for correct responses and on the recognition error rates, with age as a between-participants variable and probe condition as a within-participants variable. All of the analyses in this study were conducted with both participants $\left(F_{1}\right)$ and items $\left(F_{2}\right)$ as random effects. An alpha level of $p<$ .05 was used for all significance tests, unless otherwise noted.

Probe recognition errors. Mean percentage recognition errors as a function of age and probe condition are presented in Table 2 . There was a significant main effect of probe condition $\left[F_{1}(3,255)=31.03, M S_{\mathrm{e}}=2,024, p<\right.$ $.001, \eta^{2}=.27 ; F_{2}(3,186)=13.88, M S_{\mathrm{e}}=2,927, p<.001$, $\left.\eta^{2}=.18\right]$. Pairwise comparisons revealed that, relative to the baseline, the readers made fewer errors in verifying the previous character's name before reading the character manipulation paragraph $\left[t_{1}(86)=4.25, p<.001\right.$; $\left.t_{2}(63)=3.21, p<.005\right]$ and after reading the character manipulation paragraph in which the target character was rementioned $\left[t_{1}(86)=5.48, p<.001 ; t_{2}(63)=3.67, p<\right.$ $.005]$ but more errors after reading about a new character [significant by participants only; $t_{1}(86)=3.09, p<.005$; $\left.\left|t_{2}\right|<1\right]$. The overall error rates did not differ between the two age groups $\left(F_{1}<1\right.$ and $\left.F_{2}<1\right)$. Although there appeared to be a trend for the younger adults to make relatively more errors in the new condition, the age $\times$ probe condition interaction was not significant $\left[F_{1}(3,255)=\right.$ $\left.1.20, M S_{\mathrm{e}}=79, p=.31, \eta^{2}=.01 ; F_{2}<1\right]$, suggesting that the older adults did not suffer a disproportionate decrease in their accuracy when a new character was introduced. ${ }^{1}$

Probe recognition times. A significant main effect of age $\left[F_{1}(1,86)=11.16, M S_{\mathrm{e}}=3,476,531, p<.01\right.$, $\eta^{2}=.12 ; F_{2}(1,62)=27.86, M S_{\mathrm{e}}=4,285,675, p<.001$, $\left.\eta^{2}=.31\right]$ indicated that the older adults were slower in verifying the name of the previous character than were their younger counterparts. A significant main effect of probe condition $\left[F_{1}(3,258)=41.60, M S_{\mathrm{e}}=1,312,088\right.$, $p<.001, \eta^{2}=.33 ; F_{2}(3,186)=31.44, M S_{\mathrm{e}}=1,792,489$, $\left.p<.001, \eta^{2}=.34\right]$ showed that the accessibility of the previous character changed as a function of the character manipulation. However, as is shown in Figure 1, this main effect was qualified in a significant interaction between age and probe condition [significant by participants only;

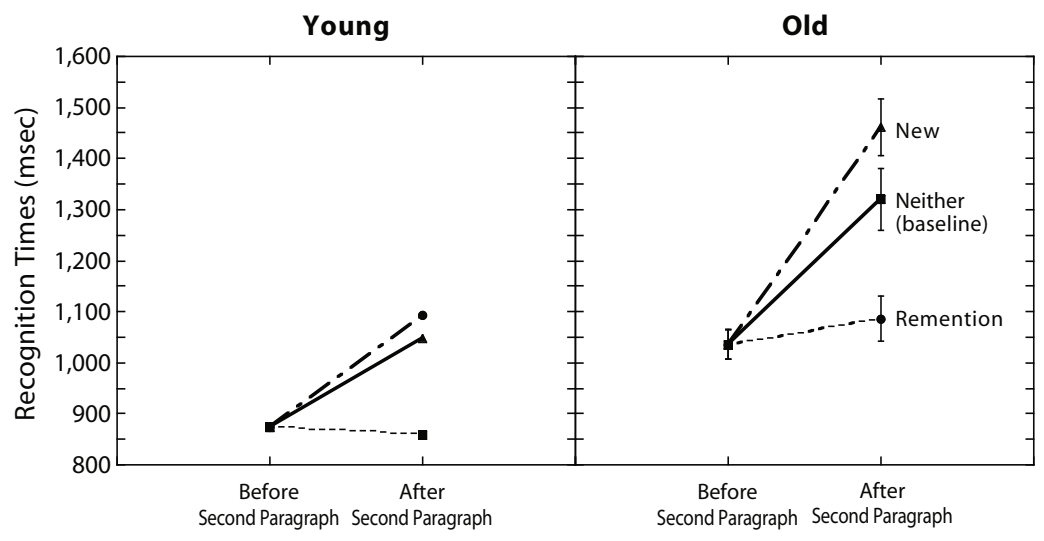

Figure 1. Probe recognition times as a function of age and probe condition for Experiment 1. 
$F_{1}(3,258)=6.05, M S_{\mathrm{e}}=190,634, p<.02, \eta^{2}=.07 ;$ $\left.F_{2}(3,186)=2.35, M S_{\mathrm{e}}=134,103, p=.08, \eta^{2}=.04\right]$. This interaction was entirely due to the fact that the recognition times for the previous character's name for the older adults were disproportionately slower than those of the younger adults when a new character was introduced. That is, the difference in recognition times between the new and baseline conditions was greater in the older group than in the younger group [significant by participants only; $\left.t_{1}(86)=2.70, p<.01 ;\left|t_{2}\right|<1\right] .^{2}$ Neither the difference in recognition times between the before and baseline conditions $\left[\left|t_{1}\right|<1 ; t_{2}(62)=1.36, p=.18\right]$ nor that between the remention and baseline conditions $\left(\left|t_{1}\right|\right.$ and $\left|t_{2}\right|<1$ ) varied with age, suggesting that the younger and older adults were similarly faster in the before and in the remention conditions than in the other conditions.

Collectively, the results from the recognition data suggest that older adults are at least as accurate as younger adults when tracking two characters in narratives but that they experience greater attentional cost in accessing a previous character if a new character is subsequently introduced (i.e., the new-baseline difference). However, older adults do not have difficulty in maintaining a protagonist in memory (i.e., the baseline-before and the baselineremention differences). This is interesting because it suggests that age-related declines in working memory may make it difficult for older adults to shift their attention among narrative characters but not necessarily to retain focus on a single character across intervening events. Consistent with this idea, we found a modest correlation between working memory span and the differences in recognition times between the new and baseline conditions $[r(84)=-.21, p=.05]$, suggesting that the smaller the working memory span was, the greater was the attentional cost in shifting between characters. ${ }^{3}$

These data represent somewhat of a challenge to the notion of situation model resilience with age (Radvansky, 1999; Stine, Soederberg, \& Morrow, 1996). Earlier exceptions to this rule have been attributed to cases in which situation model construction depends on retention of the textbase (propositional) content, which fades before a coherent situation can be constructed (Copeland \& Radvansky, 2007). This is certainly not the case here. Rather, our explanation is that the fundamental mechanisms of situation construction are preserved (e.g., characters wax and wane in activation in a way that is comparable for young and old as the narrative unfolds) but that age-related declines in working memory limit the accessibility of information that is backgrounded (Unsworth \& Engle, 2007).

\section{EXPERIMENT 2}

In Experiment 2, we further explored age differences in managing multiple characters by considering age differences in incorporating new characters into the discourse representation as a function of whether other characters existed in the narrative world (Gerrig, 1993). The participants read passages in which a target sentence mentioned a target character who (1) had been introduced earlier, so that this character was rementioned in the target sentence (same condition); (2) was introduced for the first time in the target sentence, following the introduction of another character (different condition); or (3) was introduced for the first time in the target sentence with no earlier explicit mention of any character (baseline condition). We measured reading time to encode the target character as a function of these character conditions. Assuming that it takes resources to disengage from an existing character (suppression; as in Gernsbacher et al., 2004, and in Experiment 1 in this article) to instantiate a new character, we predicted that it would take longer to encode the target character if another character had already been introduced in the discourse (in the different condition, relative to the baseline condition) and that the effect would be greater for older adults.

As in Experiment 1, we examined the accessibility of the target character by measuring accuracy and response time for verifying the name of the target character (that had just been introduced). Note that, in contrast to Experiment 1 , in this experiment, we measured the accessibility of the current character instead of the previous character, because our goal was to assess the ability to refocus attention on a new character. Assuming that readers allocated sufficient resources to fully instantiate the new character, one would expect no effect of the character condition on probe response time. However, readers do not always fully specify text representations when processing demands are high (Christianson, Hollingworth, Halliwell, \& Ferreira, 2001; Christianson, Williams, Zacks, \& Ferreira, 2006; Smallwood, McSpadden, \& Schooler, 2008; StineMorrow, Miller, \& Hertzog, 2006), so we also considered the possibility that the existence of another character in the discourse world might also affect how thoroughly the new character was instantiated. In this case, one would also expect that, relative to baseline, probe recognition latencies would be greater in the different condition and smaller in the same condition.

\section{Method}

Participants. The participants were 36 younger $(M=21$ years, range $=18-30$ years $)$ and 34 older $(M=69$ years, range $=$ 60-84 years) adults drawn from the same populations as those in Experiment 1 . The participants received $\$ 15$ for their participation, with the exception that 13 of the younger adults, who were students at the University of Illinois, participated as a requirement or for extra credit in an introductory educational psychology class. An additional 3 older participants were tested, but their data were removed for low accuracy on the probe recognition task (as is described below).

All of the participants were native speakers of English and were screened as were those in Experiment 1 . This sample of participants was $87.1 \%$ Caucasian, 5.7\% African American, 1.4\% Asian, 4.3\% multiracial, and $1.4 \%$ of unknown ethnicity. Eleven percent of the participants were Hispanic.

The older and younger groups did not differ in years of formal education completed $\left(M_{\mathrm{Y}}=14.62, S E=0.26 ; M_{\mathrm{O}}=15.12, S E=\right.$ $0.50)$ or on the WAIS-R vocabulary subtest $\left(M_{\mathrm{Y}}=47.63, S E=\right.$ $\left.1.12 ; M_{\mathrm{O}}=46.86, S E=1.78\right)(|t|<1$ for both $)$. Finally, the younger participants had an advantage over the older participants in terms of their working memory $\left[M_{\mathrm{Y}}=4.83, S E=0.16 ; M_{\mathrm{O}}=3.91, S E=\right.$ $0.17 ; t(66)=3.87, p<.001]$.

Materials and Procedure. The 24 experimental texts were modified versions of the narratives from Experiment 1, in which the target character was mentioned at the beginning of the second paragraph after an introductory paragraph with the critical manipulation. 
Table 3

Sample Experimental Narrative From Experiment 2

Paragraph 1: Character manipulation

Same condition. Patty quickly looked over the stage and saw that work needed to be done. The props were clearly in the wrong places, extra scripts were randomly scattered around, and the backdrops were still wet with paint, but at least the backdrops were finished. Patty, at this point felt a little skepticism, but there was still determination to make this production work. It did seem a bit overwhelming now that opening night was only two weeks away.

Different condition. Jack quickly looked over the stage and saw that work needed to be done. The props were clearly in the wrong places, extra scripts were randomly scattered around, and the backdrops were still wet with paint, but at least the backdrops were finished. Jack, at this point felt a little skepticism, but there was still determination to make this production work. It did seem a bit overwhelming now that opening night was only two weeks away.

Baseline condition. A quick look over the stage showed that work needed to be done. The props were clearly in the wrong places, extra scripts were randomly scattered around, and the backdrops were still wet with paint, but at least the backdrops were finished. There was, at this point a little skepticism, but there was still determination to make this production work. It did seem a bit overwhelming now that opening night was only two weeks away.

\section{Paragraph 2}

Target sentence. Patty, a stage manager, wanted everything ready for Saturday night's dress rehearsal.

Filler. The crucial step was going to be getting the actors ready. She knew that with some effort, the production would eventually come together, and with any luck at all, might even be a success. There was nothing so heartbreaking as getting bad reviews.

\section{EXPERIMENTAL TEST PROBE: PATTY}

\section{Paragraph 3: Conclusion}

It was what made the first night so important. Everyone knew it, and as opening night approached the tension got higher. It was only a high school performance, but for many of these kids it was the biggest thing they had ever done.

As is shown in Table 3, the narratives mentioned a target character (e.g., Patty) in a target sentence that was preceded by a paragraph presented in one of three conditions as described earlier: (1) the same character was described (same condition), (2) a different character (e.g., Jack) was introduced (different condition), or (3) neither the same nor a different character was mentioned (baseline condition). Each participant saw only one version of each narrative. In addition, 24 filler narratives were included (in the same style as the experimental narratives).

In order to assess the influence of prior character activation on the encoding of the target character, target sentence reading times were measured. Each of the target sentences contained between 21 and 32 syllables. The subsequent accessibility of the target character was also examined by measuring the recognition time and error rates for recognition probes after the filler paragraph. The test probes in the experimental stories were always true, and those in the filler stories were always false, so as to balance the number of correct yes and no responses for each participant.

Three material sets were created in order to counterbalance materials across experimental conditions, so that, across participants, each experimental story occurred an equal number of times in the same, different, and baseline conditions. All of the filler narratives were included in each set, and the experimental and filler narratives were presented in a fixed randomized order for all of the participants.

Each session lasted approximately $1.5 \mathrm{~h}$ and included the same components as those in Experiment 1. The participants were randomly assigned to one of three material sets, and they were asked to read the stories carefully and to respond to the name probes as quickly as possible while still being accurate. For each story, both the first and third paragraphs were presented paragraph by paragraph, but the second paragraph, which introduced the target sentence, was presented sentence by sentence, in order to measure the reading time for the target sentence. The participants were periodically asked to write a short continuation of the story that they were reading to ensure that they were reading attentively. The participants began with two practice stories.

\section{Results and Discussion}

The design of this experiment was a 2 (age: young, old) $\times 3$ (character: same, different, baseline) repeated measures ANOVA, with age as a between-participants variable and character as a within-participants variable. The primary dependent variables were: target sentence reading time (in milliseconds per syllable), probe recognition time (in milliseconds) for correct responses, and probe recognition error rates. As in Experiment 1, an accuracy criterion of better-than-chance performance in each probe condition was established; 3 older adults were removed from the final analysis by this criterion.

Because of the smaller sample in this experiment, we were especially attentive to removing outliers. First, response times greater than $3,000 \mathrm{msec}$ for the younger adults and 5,000 msec for older adults were removed. For the younger participants, $2 \%$ for the same, $3 \%$ for the different, and $1 \%$ for the baseline were removed; for the older participants, $2 \%, 5 \%$, and $1 \%$ were removed, respectively. The resulting distributions were within $2.5 \mathrm{SDs}$ of the mean for each participant; no further trimming was required.

Target sentence reading times. Reading time data are presented in Figure 2. A significant main effect of age verified that the older adults were slower in reading the target sentences than were their younger counterparts $\left[F_{1}(1,66)=12.89, M S_{\mathrm{e}}=88,810, p<.002, \eta^{2}=.16\right.$; $\left.F_{2}(1,46)=39.31, M S_{\mathrm{e}}=60,639, p<.001, \eta^{2}=.46\right]$. A significant main effect of character $\left[F_{1}(2,136)=26.04\right.$, $M S_{\mathrm{e}}=15,811, p<.001, \eta^{2}=.28 ; F_{2}(2,92)=29.40$, $\left.M S_{\mathrm{e}}=11,020, p<.001, \eta^{2}=.39\right]$ indicated that the reading times for the target sentences differed as a function of character condition. Relative to the baseline condition, reading times were longer in the different condition $\left[t_{1}(69)=3.65, p<.002 ; t_{2}(47)=3.57, p<.02\right]$ and shorter in the same condition $\left[t_{1}(69)=3.65, p<.001\right.$; $\left.t_{2}(47)=4.24, p<.001\right]$. This finding, consistent with our hypotheses about cognitive mechanisms, suggests that 


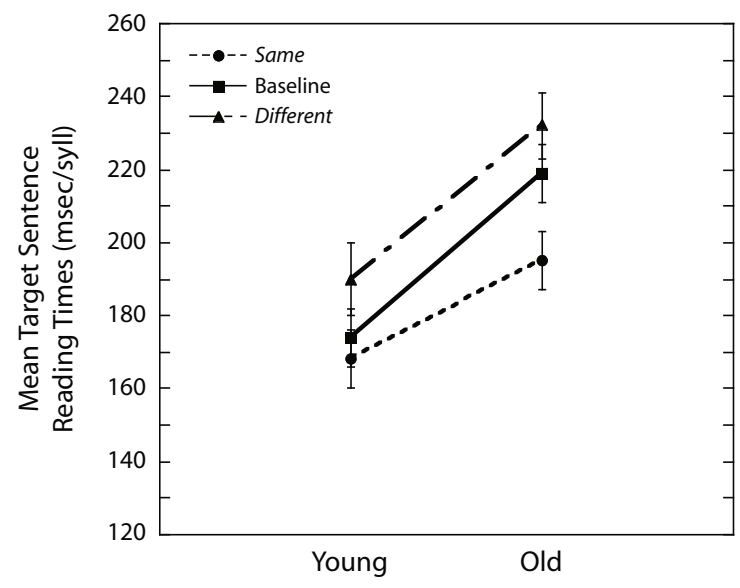

Figure 2. Mean target syllable reading times as a function of age and character condition for Experiment 2.

the existence of one character in a narrative increases the processing difficulty of encoding subsequent characters (for both younger and older adults).

The main effect of character, however, was qualified by age in a significant interaction $\left[F_{1}(2,136)=3.04, M S_{\mathrm{e}}=\right.$ $1,847, p=.05, \eta^{2}=.04 ; F_{2}(2,92)=3.56, M S_{\mathrm{e}}=1,336$, $\left.p<.05, \eta^{2}=.07\right]$ shown in Figure 2. This interaction is attributable to the fact that the older adults were differentially faster in the same condition [i.e., $t_{1}(68)=2.29, p<$ $.05 ; t_{2}(47)=4.24, p<.001$, for the baseline-same difference]. Contrary to our hypotheses about aging, however, the older readers were not differentially slower to encode the target character in the different condition. Rather, both the younger and the older adults spent similarly longer amounts of time to read the target sentence in the different condition (i.e., $\left|t_{1}\right|$ and $\left|t_{2}\right|<1$ for the different-baseline difference).

These data suggest that encoding a new character is more difficult when another character already inhabits the narrative world, presumably because of demands to disengage from the character in focus and to instantiate the new one. However, it is the case either that this was not especially difficult for older readers or that older readers were not as thorough in completing these computations. The results of Experiment 1 show that older adults can effectively suppress earlier characters, but the question remains as to whether they can also engage their attention to instantiate a new character in this context. The probe response times will address this question.

On the other hand, the difference between the same and baseline conditions was exaggerated for the older readers relative to the younger ones. Assuming that this reflects effort to encode an initial character in discourse, these data replicate earlier findings (e.g., Radvansky et al., 2001) that older adults show differential allocation to encode new characters, although we found this only in the absence of competing discourse entities.

Probe recognition errors. Mean percentage recognition errors as a function of age and character condition are shown in Table 4. The older adults tended to have higher error rates than the younger adults, but the main effect of age did not reach significance $\left[F_{1}(1,68)=2.56, M S_{\mathrm{e}}=\right.$ $339, p=.11, \eta^{2}=.04 ; F_{2}(1,46)=3.45, M S_{\mathrm{e}}=198, p=$ $\left..07, \eta^{2}=.07\right]$. The main effect of character was reliable $\left[F_{1}(2,136)=13.74, M S_{\mathrm{e}}=1,144, p<.001, \eta^{2}=.17\right.$; $\left.F_{2}(2,92)=1.49, M S_{\mathrm{e}}=793,845, p<.001, \eta^{2}=.27\right]$, indicating that, relative to the baseline, both the younger and the older readers made fewer errors in the same condition $\left[t_{1}(69)=2.53, p<.02 ; t_{2}(47)=2.27, p<.05\right]$ and more errors in the different condition $\left[t_{1}(69)=2.78, p<.01\right.$; $\left.t_{2}(47)=2.65, p<.02\right]$. The older adults tended to make more errors in the different condition than did the younger adults, however, the age $\times$ character interaction did not reach significance $\left[F_{1}(2,136)=1.78, M S_{\mathrm{e}}=148, p=\right.$ $.18, \eta^{2}=.03 ; F_{2}(2,92)=1.32, M S_{\mathrm{e}}=79, p=.27, \eta^{2}=$ .03]. The recognition error data are interesting because they suggest that a backgrounded character may interfere with instantiating a new character, even though readers allocate more effort to doing so.

Probe recognition times. A reliable main effect of age showed that the older adults took longer to verify the target character's name than did the younger adults $\left[F_{1}(1,65)=\right.$ $49.51, M S_{\mathrm{e}}=14,969,662, p<.001, \eta^{2}=.43 ; F_{2}(1,46)=$ 130.67, $\left.M S_{\mathrm{e}}=11,707,921, p<.001, \eta^{2}=.74\right]$. The accessibility of the target character varied as a function of the character condition $\left[F_{1}(2,130)=24.93, M S_{\mathrm{e}}=\right.$ $1,138,804, p<.001, \eta^{2}=.28 ; F_{2}(2,92)=17.19, M S_{\mathrm{e}}=$ $\left.662,585, p<.001, \eta^{2}=.27\right]$, but this effect was moderated by age [significant by participants only; $F_{1}(2,130)=$ $4.59, M S_{\mathrm{e}}=209,759, p<.02, \eta^{2}=.07 ; F_{2}(2,92)=1.49$, $\left.M S_{\mathrm{e}}=68.584, p=.23, \eta^{2}=.03\right]$. As is shown in Figure 3 , the interaction reflected the fact that the older adults were disproportionately slower in the different condition. Thus, the older adults showed difficulty accessing the new character that had been encoded when another character was already featured in the narrative. Considering the results of the reading time and recognition performance together, the results suggest that the older adults in our study were sensitive to the difficulty of encoding a new character in a narrative inhabited by other characters (i.e., they increased their reading time allocation as did the younger participants), but they did not allocate sufficient effort to instantiate the new character as thoroughly (i.e., given the fact that slowing-Hartley, Stojack, Mushaney, Annon, \& Lee, 1994; Salthouse, 1996-comparable outcomes in the representations for young and old participants would presumably require overallocation). Thus, even though the older adults did allocate more time to process the introduc-

Table 4

Means and Standard Errors of Recognition Errors (\%) As a Function of Age and Character Condition for Experiment 2

\begin{tabular}{|c|c|c|c|c|c|c|}
\hline \multirow[b]{2}{*}{ Character Condition } & \multicolumn{2}{|c|}{ Young } & \multicolumn{2}{|c|}{ Old } & \multicolumn{2}{|c|}{$\begin{array}{c}\text { All } \\
\text { Participants }\end{array}$} \\
\hline & $M$ & $S E$ & $M$ & $S E$ & $M$ & $S E$ \\
\hline Same & 2.42 & 0.99 & 4.10 & 1.02 & 3.26 & 0.71 \\
\hline Different & 7.99 & 2.07 & 13.60 & 2.13 & 10.80 & 0.45 \\
\hline Baseline & 5.90 & 1.59 & 6.25 & 1.63 & 6.08 & 1.14 \\
\hline Overall & 5.44 & 1.11 & 7.98 & 1.14 & 6.71 & 0.80 \\
\hline
\end{tabular}




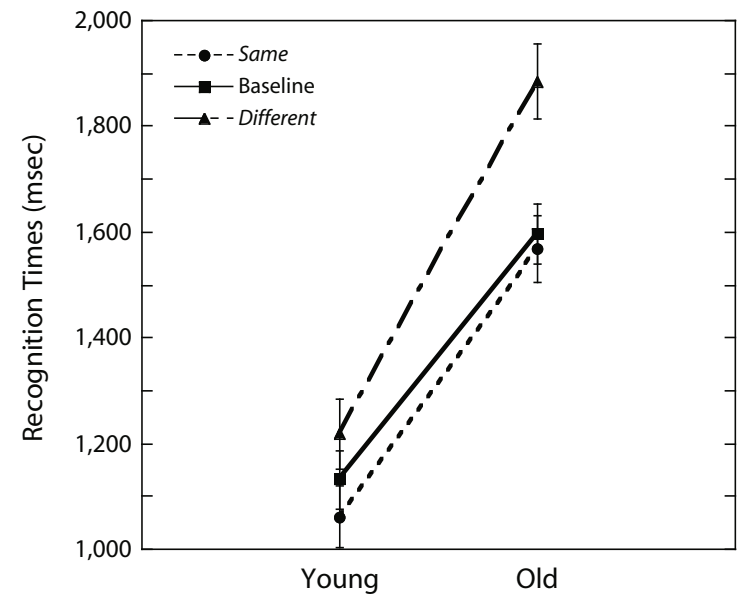

Figure 3. Probe recognition times as a function of age and character condition for Experiment 2.

tion of a new character, it was not sufficient for encoding the character as thoroughly as the young adults did, and so the new character was less accessible when probed.

As in Experiment 1, we examined whether the attentional cost in the different condition (the different-baseline difference) was related to working memory. This effect was in the predicted direction $[r(69)=-.20, p=.12]$ but did not reach significance with this smaller sample.

Finally, we note in Figure 3 that characters that were introduced for the first time in the target sentence, and those that were rementioned (i.e., the baseline-same contrast) were similarly accessible for older readers $\left(\left|t_{1}\right|\right.$ and $\left|t_{2}\right|<1$ ). This result aligns with the findings from the reading time in which older adults allocate disproportionate effort in the baseline relative to the same condition. This was apparently sufficient effort to create a character representation that was at least as durable across a couple of paragraphs as a character that was recently mentioned.

\section{CONCLUSIONS}

Although there is little evidence for an age-related decline in the understanding of situational aspects of discourse in general, and the ability to instantiate discourse entities in the language representation in particular (Noh et al., 2007; Radvansky et al., 2001; Stine-Morrow et al., 2002), there has been no systematic investigation of age differences in the ability to manage multiple characters during narrative comprehension. Previous research on narrative comprehension with younger adults (Gernsbacher et al., 2004) has shown that character information (e.g., characters' names and the objects associated with the characters) is most available when it is reintroduced, less available when neutral information is introduced, and least available when the introduction of a new character changes the focus of the story. This general result has been replicated with other aspects of the situation model, such as characters' goals (Linderholm et al., 2004), spatial and temporal framework (Morrow, Greenspan, \& Bower, 1987; Rinck \&
Bower, 2000), and emotional experience (de Vega, León, \& Díaz, 1996), suggesting that readers are likely to keep the most relevant information in their working memory to maintain the coherence of the story. This is consistent with the landscape model of reading (e.g., van den Broek et al., 2005), which suggests that the activation associated with each character waxes and wanes as characters shift. We hypothesized that if older adults' reduced working memory capacity limits the ability to track multiple characters (Morrow et al., 1994), it would be harder for them to access a previously introduced character after shifting their attention to a new character. In support of our hypothesis, the older adults incurred greater attentional cost than did the young participants under these conditions, although there was no age difference in retaining a character per se.

The results of Experiment 2 complement those of Experiment 1 by showing that it is not only more difficult to access a backgrounded character, but that it is also more difficult to encode a new character into a narrative if a protagonist has already been introduced. Although there are now several demonstrations in the literature that readers allocate more time to encode new characters (i.e., discourse entities; Noh et al., 2007; Radvansky et al., 2001; Zwaan et al., 1995), this is, to our knowledge, the first to demonstrate difficulty in the processes associated with encoding subsequent characters. Both the younger and the older adults took longer to encode a new character when another had previously been introduced. We attribute this to the need to suppress the first character (a process for which we found evidence in Experiment 1) and to instantiate the new character while retaining some representation of the original character in mind. The younger and older readers responded behaviorally in the same way in encoding the character, but this similarity in allocation of effort appeared to produce differences in the nature of the discourse representation: The older readers had special difficulty accessing characters that had been encoded when another character was already instantiated into the narrative. This pattern is reminiscent of findings in neurocognitive aging for overrecruitment of neural circuits as a means of compensation up to a point, but under-recruitment when processing difficulty exceeds some threshold (Reuter-Lorenz \& Lustig, 2005). Older readers overallocate processing time to instantiate the first character in a narrative, but may not completely keep up with the demands of multiple characters. As such, the lack of age differences in reading time in the different condition relative to the baseline suggests the possibility of underspecification of the situation by the older adults (Christianson et al., 2006).

In fact, a number of findings in recent years suggest that older readers may be especially susceptible to underspecification in language processing under some conditionsfor example, in reanalysis of syntactic analysis (Christianson et al., 2006), in integrating new concepts in sentence understanding (Shake, Noh, \& Stine-Morrow, 2009; Stine, 1990), and among the older old, following narrative plot (Stine-Morrow, Miller, Gagne, \& Hertzog, 2008). Furthermore, Daneman, Hannon, and Burton (2006) have demonstrated that older adults have to allocate more resources in order to detect an anomaly in the text to achieve a similar 
level of success to their younger counterparts. For example, when processing a locally anomalous noun phrase (NP) in Amanda was bouncing all over because she had taken too many tranquilizing sedatives, older adults had to allocate disproportionately more time to reread the locally anomalous NP to notice the anomaly at a level comparable to that of the younger adults. Thus, there is good reason to believe both that under many conditions older readers must exaggerate their allocation of effort to achieve representational outcomes comparable to those of the young and that they do not always respond to these demands.

We have argued that older adults' reduced working memory capacity may constrain their ability to track multiple characters in narrative understanding and found a small correlation between our working memory span measure and performances on character processing. There is some debate in the literature with respect to whether working memory resources are necessary for situation model processing (e.g., Friedman \& Miyake, 2000; Radvansky \& Dijkstra, 2007). The present results contribute to this discussion as well.

Finally, in contextualizing this work in the larger literature on situation model processing in language and aging (e.g., Radvansky \& Dijkstra, 2007), we note that our findings are, in large measure, consistent with the idea that the fundamental processes of situation construction are intact with aging. That is, at least within the short simple narratives in our study, both younger and older readers shift attention among characters to some extent. We argue that the boundary condition on the principle of situation model resilience with age is that working memory limits make it difficult to access backgrounded characters. Perhaps in an effort to maintain the representation of backgrounded characters at some minimal level of fidelity, older readers may underallocate attention to subsequent characters, so that the characters may be relatively less accessible, even soon after they are introduced. Thus, working memory limits may make it harder to coordinate characters simultaneously, whereas their ability to retain a single character may be preserved.

Our findings hint at possible difficulties with aging in maintaining the coherence of a story, so that future investigations need to explore this issue in greater detail, for example, how these principles play out in extended narratives in which readers construct complex representations of interrelated characters, possible augmentation of character representations through discourse elaboration, and individual differences in heuristics that readers employ in specifying the narrative representation. Our results also suggest possible avenues for text engineering (e.g., highlighting character names or search capabilities in electronic formats) that might enhance the narrative experience for readers who, regardless of age, have some limitations on working memory capacity.

\section{AUTHOR NOTE}

We are grateful for support from National Institute on Aging Grant R01 AG13935. We thank Shoshana Hindin, Micaela Chan, Mandy Amsler, and Mashone Parker for help with participant testing, scoring, and data entry. We are also grateful to Dan Morrow, Kiel Christianson, Jose Mestre, Jeanine Parisi, Matt Shake, and Xufei Gao for helpful com- mentary on earlier versions of this article. Partial results were presented at American Psychological Association meetings in San Francisco (August 2007) and in Boston (August 2008). Correspondence concerning this article should be addressed to S. R. Noh, Department of Educational Psychology, University of Illinois at Urbana-Champaign, 226 Education Building, 1310 South Sixth Street, Champaign, IL 61820-6990 (e-mail: snoh@illinois.edu).

\section{REFERENCES}

Brown, J. A., Fishco, V. V., \& Hanna, G. (1993). Nelson-Denny reading test: Manual for scoring and interpretation, Forms $G \& H$. Rolling Meadows, IL: Riverside.

Christianson, K., Hollingworth, A., Halliwell, J. F., \& FerREIRA, F. (2001). Thematic roles assigned along the garden path linger. Cognitive Psychology, 42, 368-407.

Christianson, K., Williams, C. C., Zacks, R. T., \& Ferreira, F. (2006). Younger and older adults' "good-enough" interpretations of garden-path sentences. Discourse Processes, 42, 205-238.

Chute, D. L., \& Westall, R. F. (1996). Power laboratory. Devon, PA: MacLaboratory.

Cohen, J., Cohen, P., West, S. G., \& Aiken, L. S. (2003). Applied multiple regression/correlation analysis for the behavioral sciences (3rd ed.). Hillsdale, NJ: Erlbaum.

Copeland, D. E., \& Radvansky, G. A. (2007). Aging and integrating spatial mental models. Psychology \& Aging, 22, 569-579.

Daneman, M., \& Carpenter, P. A. (1980). Individual differences in working memory and reading. Journal of Verbal Learning \& Verbal Behavior, 19, 450-466.

Daneman, M., Hannon, B., \& Burton, C. (2006). Are there agerelated differences in shallow semantic processing of text? Evidence from eye movements. Discourse Processes, 42, 177-203.

DE Vega, M., León, I., \& Díaz, J. M. (1996). The representation of changing emotions in reading comprehension. Cognition \& Emotion, 10, 303-321.

Friedman, N. P., \& Miyake, A. (2000). Differential roles for visuospatial and verbal working memory in situation model construction. Journal of Experimental Psychology: General, 129, 61-83.

GERNSBACHER, M. A. (1990). Language comprehension as structure building. Hillsdale, NJ: Erlbaum.

Gernsbacher, M. A. (1997). Group differences in suppression skill. Aging, Neuropsychology, \& Cognition, 4, 175-184.

Gernsbacher, M. A., Robertson, R. R. W., Palladino, P., \& WerNER, N. K. (2004). Managing mental representations during narrative comprehension. Discourse Processes, 37, 145-164.

Gerrig, R. J. (1993). Experiencing narrative worlds. New Haven: Yale University Press.

Gerrig, R. J., \& McKoon, G. (2001). Memory processes and experiential continuity. Psychological Science, 12, 81-85.

Hartley, J. T., Stojack, C. C., Mushaney, T. J., Annon, T. A. K., \& LEE, D. W. (1994). Reading speed and prose memory in older and younger adults. Psychology \& Aging, 9, 216-223.

Johnson, R. E. (2003). Aging and the remembering of text. Developmental Review, 23, 261-346.

Lea, R. B., Mason, R. A., Albrecht, J. E., Birch, S. L., \& Myers, J. L. (1998). Who knows what about whom: What role does common ground play in accessing distant information? Journal of Memory \& Language, 39, 70-84.

Light, L. L., \& CAPPS, J. L. (1986). Comprehension of pronouns in young and older adults. Developmental Psychology, 22, 580-585.

Linderholm, T., Gernsbacher, M. A., van den Broek, P., Neninde, L., Robertson, R. R. W., \& Sundermier, B. (2004). Suppression of story character goals during reading. Discourse Processes, 37, 67-78.

Morrow, D. G., Altieri, P. A., \& Leirer, V. O. (1992). Aging, narrative organization, presentation mode, and referent choice strategies. Experimental Aging Research, 18, 75-84.

Morrow, D. G., Greenspan, S. L., \& Bower, G. H. (1987). Accessibility and situation models in narrative comprehension. Journal of Memory \& Language, 26, 165-187.

Morrow, D. G., Leirer, V. O., \& Altieri, P. A. (1992). Aging, expertise, and narrative processing. Psychology \& Aging, 7, 376-388.

Morrow, D. G., Leirer, V. O., Altieri, P. A., \& Fitzsimmons, P. 
(1994). Age differences in updating situation models from narratives. Language \& Cognitive Processes, 9, 203-220.

Noh, S. R., Shake, M. C., Parisi, J. M., Joncich, A. D., Morrow, D. G., \& STine-Morrow, E. A. L. (2007). Age differences in learning from text: The effects of content preexposure on reading. International Journal of Behavioral Development, 31, 133-148.

RADVANSKY, G. A. (1999). Aging, memory, and comprehension. Current Directions in Psychological Science, 8, 49-53.

Radvansky, G. A., \& CURIEL, J. M. (1998). Narrative comprehension and aging: The fate of completed goal information. Psychology \& Aging, 13, 69-79.

Radvansky, G. A., Curiel, J. M., Zwaan, R. A., \& Copeland, D. E. (2001). Situation models and aging. Psychology \& Aging, 16, 145-160.

Radvansky, G. A., \& Dijkstra, K. (2007). Aging and situation model processing. Psychonomic Bulletin \& Review, 14, 1027-1042.

RAPP, D. N., \& VAN DEN BroeK, P. (2005). Dynamic text comprehension: An integrative view of reading. Current Directions in Psychological Science, 14, 276-279.

Reuter-LorenZ, P. A., \& Lustig, C. (2005). Brain aging: Reorganizing discoveries about the aging mind. Current Opinion in Neurobiology, 15, 245-251.

RINCK, M., \& Bower, G. H. (2000). Temporal and spatial distance in situation models. Memory \& Cognition, 28, 1310-1320.

RincK, M., \& Weber, U. (2003). Who when where: An experimental test of the event-indexing model. Memory \& Cognition, 31, 1284-1292.

Salthouse, T. A. (1996). The processing-speed theory of adult age differences in cognition. Psychological Review, 103, 403-428.

Shake, M. C., Noh, S. R., \& Stine-Morrow, E. A. L. (2009). Age differences in the effects of conceptual integration training on resource allocation in sentence processing. Applied Cognitive Psychology, 23, 561-578.

Smallwood, J., McSpadden, M., \& Schooler, J. W. (2008). When attention matters: The curious incident of the wandering mind. Memory \& Cognition, 36, 1144-1150.

SoederberG, L. M., \& Stine, E. A. L. (1995). Activation of emotion information in text among younger and older adults. Journal of Adult Development, 2, 23-36.

STINE, E. A. L. (1990). On-line processing of written text by younger and older adults. Psychology \& Aging, 5, 68-78.

Stine, E. A. L., \& HindMAN, J. (1994). Age differences in reading time allocation for propositionally dense sentences. Aging \& Cognition, 1, 2-16.

Stine, E. A. L., Soederberg, L. M., \& Morrow, D. G. (1996). Language and discourse processing through adulthood. In F. BlanchardFields \& T. M. Hess (Eds.), Perspectives on cognition in adulthood and aging (pp. 255-290). New York: McGraw-Hill.

Stine-Morrow, E. A. L., Miller, L. M. S., Gagne, D. D., \& HertzoG, C. (2008). Self-regulated reading in adulthood. Psychology \& Aging, 23, 131-153.

Stine-Morrow, E. A. L., Miller, L. M. S., \& Hertzog, C. (2006). Aging and self-regulated language processing. Psychological Bulletin, 132, 582-606.

Stine-Morrow, E. A. L., Morrow, D. G., \& Leno, R., III (2002). Aging and the representation of spatial situations in narrative understanding. Journals of Gerontology, 57B, P291-P297.
Therriault, D. J., Rinck, M., \& ZwaAn, R. A. (2006). Assessing the influence of dimensional focus during situation model construction. Memory \& Cognition, 34, 78-89.

Thornton, R., \& Light, L. L. (2006). Language comprehension and production in normal aging. In J. E. Birren \& K.W. Schaie (Eds.), Handbook of the psychology of aging (6th ed., pp. 129-161). Burlington, MA: Elsevier.

Unsworth, N., \& Engle, R. W. (2007). The nature of individual differences in working memory capacity: Active maintenance in primary memory and controlled search from secondary memory. Psychological Review, 114, 104-132.

VAN DEN BRoeK, P., RAPP, D. N., \& Kendeou, P. (2005). Integrating memory-based and constructionist processes in accounts of reading comprehension. Discourse Processes, 39, 299-316.

WeCHSLER, D. (1981). Wechsler Adult Intelligence Scale-Revised (7th ed.). San Antonio: Psychological Corporation.

Zwan, R. A., Magliano, J. P., \& Graesser. A. C. (1995). Dimensions of situation model construction in narrative comprehension. Journal of Experimental Psychology: Learning, Memory, \& Cognition, 21, 386-397.

ZWAAN, R. A., \& RADVANSKY, G. A. (1998). Situation models in language comprehension and memory. Psychological Bulletin, 123, 162-185.

ZWAan, R. A., \& Rapp, D. N. (2006). Discourse comprehension. In M. A. Gernsbacher \& M. A. Traxler (Eds.), Handbook of psycholinguistics (2nd ed., pp. 725-764). San Diego: Academic Press.

\section{NOTES}

1. The lack of age differences in the error data might be due to the fact that a relatively large amount of the older adults' data was removed from the analysis because of these participants' high error rates. Therefore, we reanalyzed the error data on the basis of all of the participants (including those previously excluded); this did not change the pattern of results [probe condition: $F_{1}(3,297)=38.43, M S_{\mathrm{e}}=9051.12, p<.001, \eta^{2}=.28$; age: $F_{1}(1,99)=1.66, M S_{\mathrm{e}}=633.19, p=.20, \eta^{2}=.02$; age $\times$ probe condition interaction: $\left.F_{1}(3,297)=1.70, M S_{\mathrm{e}}=399.34, p=.19, \eta^{2}=.17\right]$.

2. Given the trend toward low accuracy for the young group, it was also possible that younger and older adults exhibited different trade-offs between speed and accuracy (maybe older adults were slower because they were more accurate). To rule this possibility out, we reanalyzed the recognition time data after excluding the participants who made high error rates $(>20 \%)$ in the new condition (which resulted in removing 11 young and 6 old readers). This equated the error rates between the two age groups in the new condition $\left(M_{\mathrm{Y}}=5.4\right.$ and $\left.M_{\mathrm{O}}=5.8\right)$. This did not substantially change our finding: the age $\times$ probe condition interaction remained significant but was somewhat more reliable $\left[F_{1}(3,207)=4.73\right.$, $M S_{\mathrm{e}}=153,350, p<.01, \eta^{2}=.06 ; F_{2}(3,186)=5.46, M S_{\mathrm{e}}=477,349$, $\left.p<.005, \eta^{2}=.08\right]$.

3 . This correlation result was computed after the removal of four influential outliers on the basis of Cook's distance diagnostic statistics (Cohen, Cohen, West, \& Aiken, 2003).

(Manuscript received November 13, 2008; revision accepted for publication April 5, 2009.) 